\title{
Container Terminal Risk Evaluation and Management: A Case Study of a Moroccan Port
}

\author{
Hamid Ech-Cheikh ${ }^{1 *}$, Saâd Lissane El Haq², Abdessamad Douraid ${ }^{1}$ \\ ${ }^{1}$ Team of Production System Optimization and Energy, Laboratory of Engineering Research, Higher Institute of Maritime \\ Studies, Casablanca 20470, Morocco \\ 2 Team of Production System Optimization and Energy, Laboratory of Engineering Research, National Higher School of \\ Electricity and Mechanics, Casablanca 20470, Morocco
}

Corresponding Author Email: h.echcheikh@isem.ac.ma

https://doi.org/10.18280/ijsse.110603

Received: 27 August 2021

Accepted: 3 December 2021

\section{Keywords:}

container terminal, mapping risk approach, quantitative calculations, risk assessment, risk management

\begin{abstract}
All over the world, the ports container terminals face several challenges, one of these challenges is to prevent and manage the risks that may occur. These risks, if not well managed, can affect the overall operation of the ports and also can lead to brutal accidents. In this paper we spot the light on the risks of a container terminal in order to conduct a risk assessment by using a mapping risk approach. This mapping approach is carried out to rank the risks by taking into account their specific criticality index and their influence to a port's safety. The data was collected from the container terminal of Tangier-Med port of Morocco. Then, the quantitative calculations were made in the aim to compare the results obtained with acceptable standards, and then use them to propose measures reducing or mitigating these risks.
\end{abstract}

\section{INTRODUCTION}

The development of international trade and the growth of intercontinental trade have created a constant need for the transportation of goods. In this context, maritime transport has experienced a great development given its efficiency for the mobility of large quantities of goods. This mode of transport has been revolutionized by the introduction of containers, and the development of new platforms: Container Terminals (CT).

The invention of containerization in 1956 by the American Malcolm McLean revolutionized the sector by introducing standardization adapted to the vast majority of manufactured goods and multimodal transport. Transport goods by sea from one port to another has been done almost since the dawn of time; but today the ships are high-value goods exceeding 100 million dollars for the largest container ships, not to mention the much higher value cargo. The dangerous goods present an additional potential hazard to people, ship and the environment whether at sea, on land or at harbor. This is why the issue of adopting preventive standards becomes more and more pressing to ensure safety and environmental protection

It's important to analyze and study the risks accidents at ports, so as to identify major factors and prevent them. Furthermore, maritime logistics centers, such us large ports, often consist of a number of CT. Consequently, safe operations at ports should receive more attention to the global port management.

\section{LITERATURE REVIEW}

In port and especially in the CT various processes and operations occur all over the storage containers area. These processes and operations must respect a bunch of meticulous rules and constraints in order to guarantee storage area safety during the handling of containers. In the literature review there is a several works which discuss the risk assessment and management in CT.

For example, Lam and Lassa [1] proposed a new risk assessment framework that could evaluate at different scales of maritime port the risks arising from multi-hazards and disaster events risks. Furthermore, Thanopoulou and Strandenes [2] discussed the limitations of long-term forecasts related to shipping, and they classified risks and source of uncertainty in shipping, then they proposed a theoretical framework for analyzing the long-term uncertainty in shipping. For more results accuracy under a high uncertainty in risk data of maritime supply chains, Wan et al. [3] proposed a new model based on a fuzzy Bayesian-based FMEA which incorporate fuzzy belief rule approach with Bayesian networks. Their research concluded that the most significant risk factors are dangerous goods transportation, changing of fuel price, competition, unattractive markets, and change of exchange rates in sequence. Besides, Hamka [4] conduct their study in order to reduce work accidents at port environment, for that they used in one hand the Hazard Identification and Risk Assessment (HIRA) method through which a risk matrix was proposed for obtaining the risk level, and the other hand they established a Fault Tree Analysis (FTA) in order to root cause of the highest risk activity is investigated. Vilko and Halikas [5] used a holistic approach analyzing and identifying risks in multimodal maritime supply chain, and they proposed a new framework for classifying risks and assessing their impacts in terms of delays. Regarding the sensitivity of seaport safety, Chlomoudis et al. proposed a proactive methodology for risk evaluation of seaport, based on adaptation of the FSA (Formal Safety Assessment) for ships. The proposed methodology aims to offer a standardized approach for PRA (Port Risk Assessment) based on empirical study utilizing the historical record of encountered accidents with regard to their frequency 
of occurrence and their impact upon the human and environmental resources of the port [6]. To evaluate risk, Kang et al. [7] proposed a fire dynamics simulator and a decision tree to systematically determine the main control board fire. Hsieh et al. [8] proposed an assessment framework which helps decision-makers understand the interdependent vulnerabilities and their impact on critical infrastructure like commercial port, and the authors adopt the appropriate strategies for the mitigation of losses, and preparedness. Rigas and Sklavounos [9] evaluated the risks at a harbor that unload and store a large dangerous goods cargo by using the breeze hazard professional software package.

Other researchers pay more attention to the prevention and management of risk factors which have negative impact on the safety of the CT. For example, Rekik et al. [10] established an architecture for a multi agent solution for stacking container including containers with dangerous goods. Also, Rekik and Elkosantini [11] proposed a solution to determine the most suitable container location, with the ability to handle dangerous containers. This solution is based on a multi-agent approach. A Belief Desire-Intention (BDI) model was proposed for the development of the different agents constituting the system. Chou and Fang [12] established a method for cargo stowage planning which addresses both the safety issues involved in stowage planning and the interdependent relationship between terminal storage operations and containership cargo handling operations. The authors studied five cases in order to illustrate the effectiveness of their stowage planning methods. Alyami et al. [13] proposed a novel method which aims to facilitate the assessment of container terminal risks using the Failure Mode and Effects Analysis (FMEA). Their methods incorporate both Fuzzy Rule-Based Bayesian Network (FRBN) and Evidential Reasoning (ER). The new approach can be tailored for a wide range of applications in different safety and reliability engineering and management systems, particularly when real time risk ranking is needed.

\section{OVERVIEW OF CT OPERATIONS AND PROBLEM STATEMENT}

A CT is an essential part of a port, it is where all containers are stored and treated. The storage zone is divided into blocks. On each block containers are arranged in rows and slots (piles of at most 4 containers high); Spaces between two rows allow a safe circulation of handling equipment. This handling equipment is required for a specific management of terminal. It transfers containers within terminal and transship them. Common sorts of handling equipment are chassis-based transporters, straddle carriers, quay crane, rubber-tired gantry crane and rail mounted gantry crane [14]. In a terminal, there are three main activities relating to containers:

(1) Unloading: containers are discharged from a ship or other transport mode like trucks or train, in order to be transferred to the storage area using handling equipment.

(2) Staking: containers are stored in a reserved area, respecting physical constraints and regulations.

(3) Loading: containers leave storage area and are loaded to be transported by train or ship.

This paper focuses on the stacking activities, and the storage area where containers are moved by Straddle Carriers. When a container is moved from one area to another, within the terminal.

\section{METHODOLOGIES OF RISK ASSESSMENT}

\subsection{Risk assessment approaches}

The Failure Mode and Effects Analysis (FMEA) is extensively used method for hazard identification and risk analysis due to its visibility and easiness [15]. The FMEA method calculation is based on three fundamental attributes: likelihood (L), consequence severity (C), and probability of failures being undetected $(\mathrm{P})$ that are employed to assess the safety level of a failure. The method has incorporated advanced uncertainty modelling techniques such as fuzzy sets, grey theory, Bayesian Network (BN) and Evidential Reasoning (ER) to facilitate its practical applications in maritime and offshore engineering safety [16], system reliability and failure mode analysis [15], engineering system safety [17] and maritime port security [18]. Among the quantitative development of FMEA, a FRBN approach using Bayesian Network (BN) mechanism to conduct fuzzy rule based (FRB) risk inference in order to achieve sensitive failure priority values based on domain expert knowledge, which has been proposed and applied by Yang et al. [18] and Alyami et al. [19]. A risk-based decision tool for effective seaport hazardous events (HEs) risk evaluation was developed [13]. The purpose of this development, was about to use the rational distribution structure on Degree of Belief (DoB) to model the rule base between the four risk parameters and risk evaluation of the identified HEs in a container port operational system.

Furthermore, the American Society of Safety Engineers' publication Risk Assessment Techniques is the American adaptation of ISO31010: 2009 identifies six different types of risk assessment tool [20]:

(1) Lookup methods: checklists, preliminary hazard analysis

(2) Supporting methods: structure interviews and brainstorming.

(3) Scenario analysis: root cause analysis, fault tree analysis

(4) Function analysis: failure mode and effects analysis (FMEA), hazard and operability (HAZOP) study.

(5) Controls assessment: layers of protection analysis, bowtie analysis.

(6) Statistical techniques: Markov analysis, Monte Carlo analysis.

\subsection{Risk assessment procedure}

In this study, we have collected data through observation of container stocking operations at the CT of Tangier-Med port, which consider as one of the largest and most important port of the Kingdom of Morocco, and through interviews with operators and supervisors who worked at the stockage area. Also, the collected data was obtained from accident statistics saved by the port administration. Based on all of this data hazards were identified for each activity being carried out, then risk assessment was conducted using risk matrix to identify the risk level of each activity being investigated based on the following formula: $\mathrm{CI}=\mathrm{FI} \times \mathrm{SI}$. By comparing the quantitative results with acceptable standards, we were able to obtain the results of the assessment order to suggest measures to avoid or reduce risks.

Our survey was structured in the form of closed questions and scale questions (scoring). We have avoided asking openended questions so as not to generate evasive answers. The questions in the survey relate to the following points: 
(1) Identification of the risk and its category (Health / safety, Environment, Finance, Community / Brand, Security);

(2) The magnitude of the consequences of the risk according to the level of severity corresponding to each level of the magnitude of the consequences as described on the Table 1.

(3) The probability of the risk according to the following scale described on the Table 2 .

(4) Then the assessment of the extent of the consequences of the risk on the main parties, the criteria for assessing the significance of the risk are given in the Table 3.

(5) The criticality CI (Criticality Index) of the risks is the product of the values gravity SI (Severity Index), and the PI (Probability Index):

Table 1. Severity index level

\begin{tabular}{|c|c|c|}
\hline SI & Severity & Definition \\
\hline 1 & very low & $\begin{array}{l}\text { The impact on the company's objectives } \\
\text { would be negligible. It is almost certain } \\
\text { that the objectives will be achieved: Very } \\
\text { low Severity }\end{array}$ \\
\hline 2 & low & $\begin{array}{c}\text { The impact on the company's objectives } \\
\text { would be low. The targets are likely to } \\
\text { be met, but there is a low probability of } \\
\text { failure: Low severity }\end{array}$ \\
\hline $\mathbf{3}$ & Moderate & $\begin{array}{l}\text { The impact on the company's objectives } \\
\text { would be moderate. The goals would be } \\
\text { achieved as it might fail: Grave fullness }\end{array}$ \\
\hline 4 & High & $\begin{array}{l}\text { The impact on the company's objectives } \\
\text { would be strong. The goals should } \\
\text { probably fail, but there is still a low } \\
\text { probability of success. }\end{array}$ \\
\hline 5 & very high & $\begin{array}{c}\text { The consequences on the objectives of } \\
\text { the company would be extremely high: } \\
\text { Very serious }\end{array}$ \\
\hline
\end{tabular}

Table 2. Probability index level

\begin{tabular}{ccc}
\hline PI & Probability & Definition \\
\hline $\mathbf{1}$ & Rare & Very low likelihood of risk occurring. \\
$\mathbf{2}$ & Unlikely & Low probability that risk will occur. \\
$\mathbf{3}$ & Possible & The risk may or may not appear. The risk \\
$\mathbf{4}$ & Likely & statement can be as true as it is false. \\
$\mathbf{5}$ & $\begin{array}{c}\text { Almost } \\
\text { certain }\end{array}$ & $\begin{array}{c}\text { Very high likelihood that the risk occur. } \\
\text { There is virtually no uncertainty about this. }\end{array}$ \\
\hline
\end{tabular}

Table 3. Criticality index level

\begin{tabular}{ccc}
\hline CI & Criticality & Definition \\
\hline $\mathbf{5}$ & $\begin{array}{c}\text { Negligible } \\
\text { risk }\end{array}$ & $\begin{array}{c}\text { Very low risk. Under these } \\
\text { circumstances, opportunities for } \\
\text { optimization or improvement could be } \\
\text { identified. }\end{array}$ \\
$\mathbf{[ 5 , 1 5 ]}$ & $\begin{array}{c}\text { Risk to } \\
\text { follow }\end{array}$ & $\begin{array}{c}\text { Average level of risk, which requires } \\
\text { maintaining current controls or other } \\
\text { interventions. }\end{array}$ \\
& $\begin{array}{c}\text { Risk to } \\
\text { treat }\end{array}$ & $\begin{array}{c}\text { High level of risk, the company should } \\
\text { prioritize the triggering of actions to } \\
\text { control the risk. }\end{array}$ \\
\hline
\end{tabular}

\subsection{Problem statement}

The aspects taken into account in this work relate to risk assessment in a CT. Consequently, the main problem to be solved is stated as follows:

"How can we manage the risks associated with the container handling activity, at the level of a supply chain characterized by a high distribution of tasks and by the heterogeneity of its stakeholders?"

This present work then attempts to undertake all the necessary measures to perfect the functioning of the port, namely, among other things, to efficiently manage its possible risks. To meet this need, we aim through this project, to identify risks within a $\mathrm{CT}$, and by making an inventory of the risks that exist in a $\mathrm{CT}$, their economic impacts, humans, etc. We will apprehend the analysis and the identification of its risks by making use of a survey among the actors of the port flow, making it possible to bring elements of answer on the behavior of the actors and the environment of the market being the object of our study.

In this work we assess and manage the risk of Tangier-Med CT. The Port is located on the second busiest seaway in the world, the Strait of Gibraltar with more than 100,000 ships per year. Its main activity is the transshipment of containers.

The port complex (Figure 1) consists of two large enclosures for receiving ships, the first sea basin of which is operated by two international operators in terms of managing port CT.

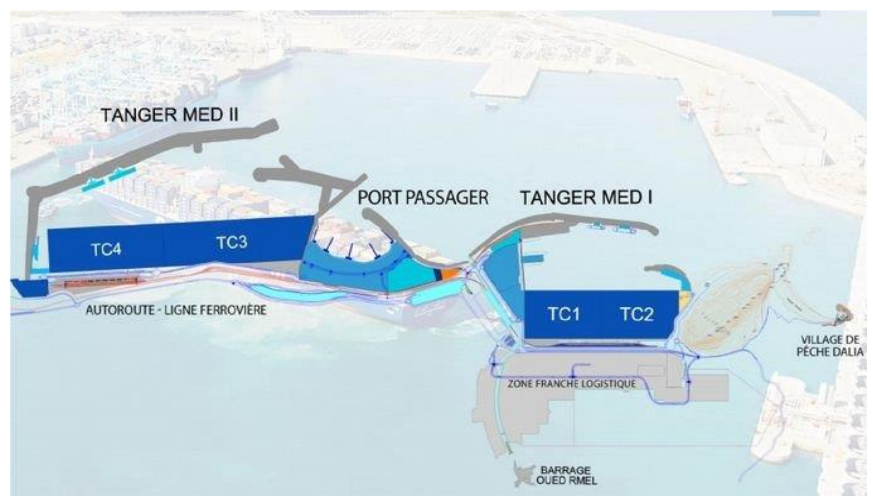

Figure 1. Tangier-Med Port

\section{RESULTS AND DISCUSSION}

\subsection{Risk assessment}

Through the use of data collected from our questionnaire, it emerges that the handling activity is subject to a plethora of risks. These are likely to occur due to several factors, the consequences of which affect the normal operation of the terminal and impact its operational performance. The risk analysis matrix that we have established for this project as a whole is represented as follows Table 4.

The results of this investigation clearly show that the risks identified during the container loading operation are generally at the high-risk level "inherent 'extreme' risk", and the Table 5 below summarize the collected data. These risks are closely linked to the handling equipment itself, indeed, we note that shocks during operation, falling, overturning or collision, and the failure of lifting devices or handling equipment are the factors that most influence the efficiency of handling flow. 
Table 4. Sample of risks identified

\begin{tabular}{|c|c|c|c|c|c|}
\hline \multirow{2}{*}{ Risk Category } & \multirow{2}{*}{ Risk } & \multirow{2}{*}{ Consequence } & \multicolumn{3}{|c|}{ Inherent Risk Score } \\
\hline & & & SI & PI & CI \\
\hline Health / Safety & $\begin{array}{l}\text { Vessel Vs STS accident by the swinging } \\
\text { of the spreader }\end{array}$ & $\begin{array}{l}\text { Equipment falling down, Availability, cost and } \\
\text { safety impact }\end{array}$ & 5 & 3 & 15 \\
\hline Environment & High wind & Cranes accident with others /RTG fall down & 5 & 4 & 20 \\
\hline Finance & Power blackout & Risk of equipment and vessel blocked & 5 & 4 & 20 \\
\hline Finance & Power cable of the crane cut & Crane stoppage and impact on other Cranes & 5 & 3 & 15 \\
\hline Health / Safety & Structure crack/broken & $\begin{array}{l}\text { EQ Availability impact, cost impact and } \\
\text { maintenance impact }\end{array}$ & 5 & 3 & 15 \\
\hline Environment & Leaking of an IMO container & Fire and explosion /Business impact & 5 & 3 & 15 \\
\hline Finance & STS VS EQ accident & Damage of QC or other equipment & 3 & 3 & 9 \\
\hline Health / Safety & Accident STS Vs STS & Cranes Damage and safety impact & 4 & 4 & 16 \\
\hline Finance & Maintenance failure (task, periodicity) & EQ safety and reliability & 4 & 2 & 8 \\
\hline Finance & Overuse & EQ quick Degradation & 4 & 1 & 4 \\
\hline Finance & Part Out of stock & Equipment unavailability performance impact & 4 & 3 & 12 \\
\hline Health / Safety & $\begin{array}{c}\text { Emergency stops of equipment not } \\
\text { working }\end{array}$ & Accidents & 4 & 3 & 12 \\
\hline Finance & $\begin{array}{l}\text { Risk that Maintenance and Repair cause a } \\
\text { significant loss of availability }\end{array}$ & Broken Parts / big damage and availability impact & 5 & 5 & 25 \\
\hline Security & Cyber-attack or Virus & Operations Stop & 5 & 1 & 5 \\
\hline Health / Safety & Gantry rail issue & $\begin{array}{l}\text { Gantry rail deviation and falling down blocks of } \\
\text { containers }\end{array}$ & 4 & 1 & 4 \\
\hline Finance & Gearbox broken & Equipment unavailability and falling containers & 5 & 3 & 15 \\
\hline
\end{tabular}

Table 5. Synthesis of risk assessment survey

\begin{tabular}{cc}
\hline Risk report summary & \\
\hline Total hazard / aspect identified & 46 \\
Total inherent 'extreme' risk & 20 \\
Total residual 'extreme' risk & 0 \\
Total 'health / safety' risk category & 18 \\
Total 'environmental' risk category & 4 \\
Total 'Finance' risk category & 23 \\
Total 'security' risk category & 1 \\
Total 'Community / Brand' risk category & 0 \\
\hline
\end{tabular}

To have a clear vision of the impact of these risks on the operation of the terminal, we have tried to group them into categories (Figure 2). The results of this graph show that the most dominant category is that impacting the business economy with a rate of $50 \%$ followed by the impact on safety and people with a percentage of $39.13 \%$ and on Environment we recorded a rate of $8.69 \%$ on the other hand the risks influencing the operational safety of handling operations represent only $2.17 \%$.

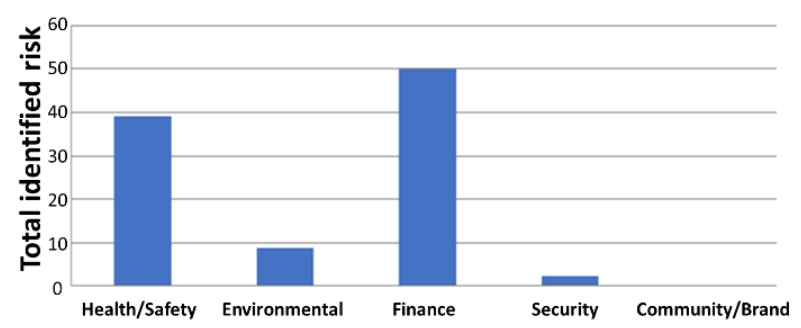

Figure 2. Repartition of the identified risk

\subsection{Risk management}

Risk prevention and treatment consists in eliminating the major causes of an unforeseen event and in effectively controlling the parameters that can lead to it and in putting in place protection to reduce the risks run by the terminal. The prerequisite for any risk management policy lies in the detailed analysis of the risks that a supply chain may face. Knowing your risks is not enough, you have to be able to face them when they arise. It is in the interest of developing a risk control plan, in order to prevent their occurrence and proliferation.

(1) Preventive maintenance of container handling equipment, the aim of which is to extend its service life by anticipating potential breakdowns, reducing their probability of failure or deterioration and eliminating the causes of serious accidents.

(2) Internal truck speed limits $(\mathrm{Vmax}=30 \mathrm{~km} / \mathrm{h})$.

(3) Raising driver awareness of the transport of dangerous goods by road.

(4) Stopping of handling operations when the wind speed exceeds $23 \mathrm{~m} / \mathrm{s}$ : securing of handling equipment, control of the wind speed.

(5) Application of segregation rules (IMDG code).

(6) Stacking limited to 3 levels for containers of dangerous products and location of containers at the end of the blocks.

(7) Compliance with traffic rules on platforms and solid land; container storage mode, floor marking, definition of traffic direction.

(8) Lifting devices and handling equipment are subject to regulatory inspections: checking the condition of the handling devices, checking the lifting capacity.

Figure 3 presents the result of the impact of the development of this action plan and gives quantitative information on the effectiveness of the proposed control elements. Indeed, $13 \%$ of the measures contributed to the complete elimination of the risks. $5 \%$ of the controls were able to considerably reduce the extent of the danger and minimize their consequences. In contrast, measures to design controls or place a physical barrier on the hazard by keeping or enclosing it represent $56 \%$. Unlike those aiming to set up training or procedures which hold $23 \%$. Knowing that the measures that involve the commitment of staff to improve their behavior represent only $3 \%$ of the total.

After the preventive measures have been implemented, it must be checked whether they have been carried out. Likewise, the Table 6 represents the percentage of every measure which 
were held and the efficiency of the controls. It is not only a question of verifying whether the risks have been eliminated or entirely eliminated or whether they have been able to be reduced so as to be able to control them, but also whether no new risk has been created following the application of the measures. In addition, it is recommended to regularly carry out a new risk assessment, in order to determine whether the risks have indeed been definitively eliminated or whether other risks have appeared since the last assessment. It is essential to perform a risk assessment again each time there has been a change. The latter can be, for example, the installation of a new machine, the introduction of a new process or the introduction of a new product.

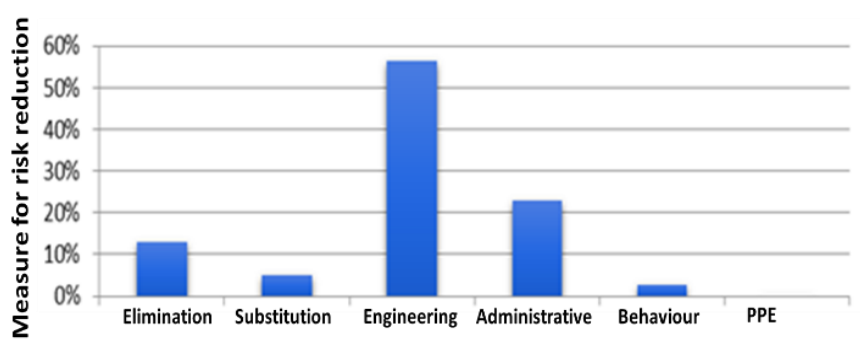

Figure 3. Controls applied repartition

Table 6. Controls efficiency

\begin{tabular}{|c|c|c|}
\hline \multicolumn{3}{|c|}{ Controls efficiency } \\
\hline Green & Yellow & Red \\
\hline 35 & 9 & 2 \\
\hline
\end{tabular}

\section{CONCLUSION}

The main objective of this article is to identify and assess the various risks of the handling activity within the container terminal. To this end, we carried out an analysis of the process of transporting a container in the CT, this step allowed us to identify all of the potential risks. Then, we detailed the risk scenarios in order to analyze their causes and consequences. To do this, we opted for the questionnaire technic in order to collect data, assess each identified risk and determine its severity and probability of occurrence. Finally, we devoted the last part of this article to the interpretation of the results of our study and to the evaluation of the impact of its risks on the operational performance of CT. It is important to take into account the result of the risk assessment since the detected risks can add up or combine their effects. In this regard, preventive measures must be put in place as a control barrier serving to reduce the costs generated by the seriousness of these risks and stop their development.

\section{REFERENCES}

[1] Lam, J.S.L., Lassa, J.A. (2017). Risk assessment framework for exposure of cargo and ports to natural hazards and climate extremes. Maritime Policy \& Management, $\quad 44(1)$ : 1-15. https://doi.org/10.1016/J.NUCENGDES.2015.04.030

[2] Thanopoulou, H., Strandenes, S.P. (2017). A theoretical framework for analysing long-term uncertainty in shipping. Case Studies on Transport Policy, 5(2): $325-$ 331. https://doi.org/10.1016/J.CSTP.2017.03.008

[3] Wan, C., Yan, X., Zhang, D., Qu, Z., Yang, Z. (2019). An advanced fuzzy Bayesian-based FMEA approach for assessing maritime supply chain risks. Transportation Research Part E: Logistics and Transportation Review, 125:

222-240. https://doi.org/10.1016/J.TRE.2019.03.011

[4] Hamka, M.A. (2017). Safety risks assessment on container terminal using hazard identification and risk assessment and fault tree analysis methods. Procedia Engineering, 194: 307-314. https://doi.org/10.1016/J.PROENG.2017.08.150

[5] Vilko, J.P., Hallikas, J.M. (2012). Risk assessment in multimodal supply chains. International Journal of Production Economics, 140(2): 586-595. https://doi.org/10.1016/J.IJPE.2011.09.010

[6] Chlomoudis, C.I., Pallis, P.L., Tzannatos, E.S. (2016). A risk assessment methodology in container terminals: The case study of the port container terminal of Thessalonica, Greece. Journal of Traffic and Transportation Engineering, 4: 251-258. https://doi.org/10.17265/23282142/2016.05.004

[7] Kang, D.I., Kim, K., Jang, S.C., Yoo, S.Y. (2015). Risk assessment of main control board fire using fire dynamics simulator. Nuclear Engineering and Design, 289:

195-207. https://doi.org/10.1016/J.NUCENGDES.2015.04.030

[8] Hsieh, C.H., Tai, H.H., Lee, Y.N. (2014). Port vulnerability assessment from the perspective of critical infrastructure interdependency. Maritime Policy \& Management, 41(6): 589-606. https://doi.org/10.1080/03088839.2013.856523

[9] Rigas, F., Sklavounos, S. (2002). Risk and consequence analyses of hazardous chemicals in marshalling yards and warehouses at Ikonio/Piraeus harbour, Greece. Journal of Loss Prevention in the Process Industries, 15(6): 531-544. https://doi.org/10.1016/S09504230(02)00030-X

[10] Rekik, I., Elkosantini, S., Chabchoub, H. (2015). RealTime Stacking System for dangerous containers in seaport terminals. IFAC-PapersOnLine, 48(3): 141-148. https://doi.org/10.1016/J.IFACOL.2015.06.072

[11] Rekik, I., Elkosantini, S. (2019). A multi agent system for the online container stacking in seaport terminals. Journal of Computational Science, 35: 12-24. https://doi.org/10.1016/J.JOCS.2019.06.003

[12] Chou, C.C., Fang, P.Y. (2021). Applying expert knowledge to containership stowage planning: An empirical study. Maritime Economics \& Logistics, 23(1): 4-27. https://doi.org/10.1057/S41278-018-0113-0

[13] Alyami, H., Yang, Z., Riahi, R., Bonsall, S., Wang, J. (2019). Advanced uncertainty modelling for container port risk analysis. Accident Analysis \& Prevention, 123: 411-421. https://doi.org/10.1016/J.AAP.2016.08.007

[14] Stahlbock, R., Voß, S. (2008). Operations research at container terminals: A literature update. OR Spectrum, 30(1): 1-52. https://doi.org/10.1007/S00291-007-0100-9

[15] Braglia, M., Frosolini, M., Montanari, R. (2003). Fuzzy criticality assessment model for failure modes and effects analysis. International Journal of Quality \& Reliability Management, 20: 503-524. https://doi.org/10.1108/02656710310468687

[16] Sii, H.S., Wang, J., Ruxton, T. (2001). Novel risk 
assessment techniques for maritime safety management system. International Journal of Quality \& Reliability Management, 18:

982-1000 https://doi.org/10.1108/02656710110407145

[17] Liu, J., Yang, J.B., Wang, J., Sii, H.S. (2005). Engineering system safety analysis and synthesis using the fuzzy rule-based evidential reasoning approach. Quality and Reliability Engineering International, 21(4): 387-411. https://doi.org/10.1002/QRE.668

[18] Yang, Z., Bonsall, S., Wang, J. (2008). Fuzzy rule-based Bayesian reasoning approach for prioritization of failures in FMEA. IEEE Transactions on Reliability, 57(3): 517528. https://doi.org/10.1109/TR.2008.928208

[19] Alyami, H., Lee, P.T.W., Yang, Z., Riahi, R., Bonsall, S., Wang, J. (2014). An advanced risk analysis approach for container port safety evaluation. Maritime Policy \& Management, 41(7): 634-650. https://doi.org/10.1080/03088839.2014.960498

[20] ANSI/ASSE Z690.3. American National Standard - Risk Assessment Techniques. Des Plains, IL: The American Society of Safety Engineers, USA, 2011. 